\title{
“Empreender para não divorciar!”: o processo de criação e estruturação organizacional de uma empresa que salvou um casamento

Jammilly Brandão ${ }^{1}$

Joelma Abrantes Guedes Temoteo ${ }^{2}$

${ }^{1}$ Instituto Federal de Educação, Ciência e Tecnologia de Brasília

${ }^{2}$ Universidade Federal da Paraíba 


\section{"Empreender para não divorciar!": o processo de criação e estruturação organizacional de uma empresa que salvou um casamento}

Resumo: Este caso para ensino apresenta a trajetória e os desafios de uma mulher decidida a empreender para salvar seu casamento. O relato narra a história de uma empresa que nasceu a partir do desejo da esposa de um chef de cozinha em abrir um restaurante no interior da Paraíba para trazer seu marido, que por motivos profissionais foi morar em São Paulo, para próximo da família. O caso mostra o perfil empreendedor e todo o processo de criação e estruturação organizacional de uma empresa no setor de alimentação, localizado em AreiaPB: o Aroma da Serra. Os dados utilizados nesse relato foram obtidos a partir de uma entrevista semiestruturada com a empreendedora Maria da Conceição. Temas como processo empreendedor, estratégias organizacionais, gestão de pessoas, estratégias de marketing e turismo de base comunitária podem ser discutidos por meio do caso, em diferentes disciplinas dos cursos de Administração, Turismo, Hotelaria e Gastronomia.

Palavras-chave: Caso para ensino. Empreendedorismo. Gestão de Pequenos Negócios.

\section{Introdução}

Este caso é inspirado em uma história real e foi desenvolvido no intuito de auxiliar professores dos cursos de Administração, Turismo, Hotelaria e Gastronomia, na abordagem de conteúdos relacionados ao empreendedorismo, administração estratégica, gestão de pessoas, marketing, turismo de base comunitária e associações, que fazem parte da estrutura curricular de cursos de nível técnico e superior.

Casos para ensino são relatos de experiências vivenciadas por pessoas e organizações, construídos com propósitos educacionais (Alberton \& Silva, 2018; Roesch, 2007). Os casos vêm sendo utilizados na formação gerencial há cerca de cem anos em universidades norteamericanas. No Brasil, o uso deste método de ensino-aprendizagem se propagou mais nas escolas de administração. No entanto, apesar da baixa produção de casos na área de turismo, hotelaria e gastronomia, esse recurso didático pode proporcionar oportunidade para aprimorar o processo de ensino e aprendizagem na formação dos profissionais dessas áreas, devido ao seu potencial enquanto recurso didático para o desenvolvimento de competências (conhecimentos, habilidades e atitudes) em sala de aula, em cursos de nível técnico, graduação e pós-graduação (Roesch, 2007).

O caso para ensino contribui para: a aplicação de conhecimentos adquiridos em um curso ou disciplina; a associação entre os conceitos teóricos e a prática de um determinado contexto profissional, organizacional ou institucional; o desenvolvimento de um pensamento sistêmico sobre o funcionamento de uma organização ou parte dela, e a compreensão da situação vivenciada por um profissional ou organização em um período de tempo determinado (Alberton \& Silva, 2018).

Muitos professores ainda confundem casos para ensino com estudos de caso, mas são coisas distintas. Um caso para ensino deve descrever uma situação para análise, fornecer 
informações e propor questões para reflexão, com o objetivo de analisar decisões tomadas por pessoas e organizações que as conduziram ao momento em questão e, assim, contribuir para o aperfeiçoamento de suas ações, com propósitos educacionais específicos. Nesse sentido, sua estrutura se divide em duas partes: a) o caso, com contexto, dilema e fechamento, e b) as notas de ensino, dirigidas ao professor, que usará o caso em sala de aula, apresentadas em folhas separadas do caso (Alberton \& Silva, 2018).

Um caso para ensino é a reconstrução de uma situação organizacional baseada em trabalho de campo ou em experiência de consultoria ou, ainda, em dados documentais e/ou bibliográficos, que possibilita uma aprendizagem significativa através da(o): a) aplicação de conhecimentos adquiridos em um curso ou disciplina; b) associação entre os conceitos teóricos e a prática de um determinado contexto profissional, organizacional ou institucional; c) Desenvolvimento de um pensamento sistêmico sobre o funcionamento de uma organização ou parte dela d) Compreensão da situação vivenciada por um profissional ou organização em um período de tempo determinado (Alberton \& Silva, 2018).

Em outras palavras, na aplicação de um caso para ensino, os alunos podem refletir sobre uma situação real de uma organização, que requer análise e tomada de decisão por meio da aplicação de conhecimentos multidisciplinares de determinada disciplina. Assim, é realizada uma articulação entre os conceitos teóricos com a prática vivenciada no mundo das organizações.

Neste caso para ensino é relatada a história de uma mulher que decidiu empreender para salvar seu casamento. A empresa nasceu a partir do desejo da esposa de um chef de cozinha em abrir um restaurante no interior da Paraíba para trazer seu marido, que por motivos profissionais tinha ido morar em São Paulo, para próximo da família.

A seguir será abordado como surgiu a ideia do negócio e como ela se transformou em realidade, com o objetivo de mostrar o perfil empreendedor e todo o processo de criação e estruturação organizacional de uma empresa do setor de alimentação, o restaurante Aroma da Serra localizado em Areia, uma cidade turística do interior da Paraíba.

\section{A ideia do negócio}

Maria da Conceição, mais conhecida como Ceicinha, nasceu em Areia, interior da Paraíba, é filha de pai e mãe comerciantes, tem 33 anos e é bióloga de formação. A ideia de empreender no segmento de alimentação na sua cidade natal surgiu com o objetivo de salvar seu casamento com o chef de cozinha, Severino, que foi morar em São Paulo em busca de melhores oportunidades de trabalho. Ceicinha o acompanhou até São Paulo, mas não conseguiu se adaptar com a rotina da cidade grande e decidiu voltar para Areia-PB, com a filha de dois anos de idade. Seu esposo não quis voltar com ela porque estava muito satisfeito com seu salário de chef e ambos decidiram manter o casamento a distância.

Com o passar do tempo, o relacionamento do casal começou a entrar em crise e Ceicinha, criando a filha praticamente sozinha, sentia-se como uma "mãe solteira". Certo dia, cansada desta situação, ela tomou uma decisão: mandou sua aliança via correio e avisou para seu esposo que ou ele voltava ou o casamento deles iria acabar.

- "Olhe, eu estou mandando a aliança pelo sedex e a gente vai se separar", decidida disse Ceicinha. 
- “Ceiça, o que é que eu vou fazer aí em Areia?”, respondeu seu esposo, Severino.

A resposta de Ceicinha foi imediata: "abrir um restaurante"! E assim emergiu a ideia do Restaurante Aroma da Serra, que surgiu não por oportunidade de negócio, mas sim por necessidade. E não apenas necessidade financeira, como acontece com grande parte dos empreendedores brasileiros, mas, principalmente, pela necessidade de restaurar uma família, de salvar um casamento. No entanto, não foi fácil convencer o seu esposo. Diante da proposta de Ceicinha, Severino argumentou: - "Mas já têm muitos restaurantes aí!". Ceicinha, irredutível, defendeu com precisão: - "Não tem o seu!"

\section{Transformando a ideia em realidade}

O esposo de Ceicinha estava muito inseguro em abrir um restaurante na cidade de Areia, mas arriscou, pois sua esposa prometeu que se não desse certo, eles voltariam juntos para São Paulo. Agora a ideia precisava sair da imaginação e virar realidade. Para isso, ela começou a planejar o negócio: onde abrir o restaurante, o que era preciso comprar para preparar e servir as refeições, qual o tipo de cardápio e serviço iriam ser adotados. Mas tudo foi feito sem um planejamento estruturado: sem elaborar um plano de negócios, sem realizar análise de mercado, sem definição de público-alvo. Tudo foi feito de maneira intuitiva.

Todo o recurso financeiro da família entrou na empreitada. Apesar de ter ganhado de seu pai o prédio para instalação do restaurante, foi preciso vender um caminhão da família, que era usado para fazer frete da Paraíba para São Paulo, e até a poupança da filha do casal precisou ser utilizada para montar o negócio. Ceicinha estava determinada a abrir o restaurante sem fazer dívidas, pois acreditava se tratar de um "tiro no escuro". Por enxergarum alto risco no negócio e não estava em seus planos se arriscar com dinheiro de terceiros.

Três dias após a reforma do prédio, o restaurante já foi inaugurado. Não dava para ser diferente, pois os recursos da família estavam acabando e todos dependiam agora do sucesso do negócio para sobreviver. Após as despesas com a construção e compra dos utensílios do restaurante, restou apenas $\mathrm{R} \$ 1.870,30$ (mil e oitocentos e setenta reais e trinta centavos). Ceicinha lembra precisamente do saldo da conta bancária da família. Era o dinheiro que tinha para as compras dos insumos para preparar as refeições e abrir o negócio.

Mas com quase tudo pronto para a inauguração do restaurante, na noite anterior ao dia de abertura do Aroma da Serra, Ceicinha lembrou que não havia feito nenhum tipo de divulgação: não tinha passado mensagem em whatsapp, não tinha mandado e-mail, não tinha postado nada nas redes sociais, não tinha colocado carro de som na rua para anunciar. Enfim, não tinha atentado para as estratégias promocionais de marketing. Nesse momento, Ceicinha se desesperou e saiu ligando para os parentes, pois acreditava que ainda que não viesse nenhum cliente, a família não iria faltar nesse momento tão importante de sua vida. Nesta noite que antecedeu a inauguração do restaurante, Ceicinha ficou fazendo ligações até a madrugada e só foi dormir às três horas da manhã do grande dia.

\section{“O grande dia” - Inauguração do Aroma da Serra}


No domingo, às onze horas da manhã do dia 23 de fevereiro de 2014, o Aroma da Serra estava com suas portas abertas à espera dos seus primeiros clientes. Até o meio dia ninguém havia chegado e Ceicinha começou a se desesperar, achando que ninguém iria aparecer. No entanto, aos poucos, foram chegando pessoas da família trazendo amigos. Passando das 13 horas, já não havia mais mesa disponível para acomodar os clientes, apesar da capacidade do restaurante acomodar até 100 comensais. Neste dia, o restaurante funcionou até às 16 horas da tarde. A equipe de funcionários era composta apenas por Ceicinha, seu esposo, e um garçom, mas com o grande movimento do restaurante, sua mãe, suas tias e até um primo e a namorada dele passaram a ajudar, pois três pessoas eram insuficientes para atender a clientela, no entanto, isso não também havia sido previsto.

No dia seguinte, por ser uma segunda-feira, a estimativa de público era bem menor, no entanto, como todos os restaurantes da cidade de Areia fecham neste dia, e só o Aroma da Serra abriu, houve mais uma vez uma grande demanda: funcionários do foro eleitoral, da vara trabalhista, das empresas da redondeza. Além disso, a divulgação "boca a boca" foi muito boa e mais uma vez o restaurante estava cheio. Novamente, Ceicinha entrou em desespero e precisou contar com a ajuda de seu pai, da sua mãe e de outros parentes para ajudar a atender os clientes.

\section{“Aos trancos e barrancos" - a trajetória e os desafios do Aroma da Serra}

Não dava para manter o negócio, improvisando garçons, cozinheiros e caixa. O sufoco que o casal vinha passando para atender a clientela fez Ceicinha refletir que era preciso recrutar e selecionar funcionários. Todavia, a falta de experiência e conhecimento fez com que ela realizasse isso também de forma intuitiva.

A empreendedora definiu que, diante de sua experiência com comércio, devido ao fato de ter crescido dentro dos empreendimentos de seus pais, ela ficaria no salão do restaurante, atendendo os clientes, e Severino, pela sua competência enquanto chef de cozinha, ficaria na cozinha. No entanto, apenas o casal não daria conta de atender a demanda do restaurante, que crescia dia a dia. Assim, ela passou a convidar pessoas da vizinhança que nunca tinha trabalhado, para assim dá-lhes uma oportunidade de emprego. Houve casos também de admissão de pessoas com experiência, que chegaram ao restaurante com "manias", que iam de encontro ao que ela queria para sua empresa. Todavia, Ceicinha tinha muita dificuldade para demitir os funcionários. Ela pensava sempre nos filhos do funcionário, que com o pai desempregado poderiam vir a passar fome. Logo, ela sempre buscava dar mais uma chance, principalmente, pelo fato de Areia ser uma cidade pequena, que não tinha tanta oportunidade de trabalho. Assim, o grande desafio para Ceicinha era encontrar o equilíbrio entre esse seu lado pessoal e materno, e o lado profissional demandado a quem gerencia um negócio.

Outra grande dificuldade enfrentada pela empreendedora foi quando a equipe de trabalho ficou constituída predominantemente por mulheres. As funcionárias eram muito difíceis de trabalhar, por serem competitivas e brigarem muito umas com as outras. O clima organizacional era péssimo, pois elas não se entendiam. Como havia um funcionário homem, Ceicinha passou a observar o seu comportamento, e percebeu que ele era mais tranquilo, que ele era prestativo com as outras funcionárias, então decidiu começar a trocar sua equipe. A princípio substituiu duas mulheres por dois rapazes que não sabiam de nada, em relação ao 
serviço de restaurante. Ceicinha precisou treiná-los, mas deu certo. Após essa experiência bem sucedida, ela substituiu todas as mulheres da sua equipe por homens.

Após essa reformulação, a empreendedora passou a ter confiança em sua equipe, inclusive, para se ausentar quando isso se faz necessário. Quando Ceicinha engravidou pela segunda vez, por exemplo, ela precisou se afastar por um mês do seu trabalho, os rapazes assumiram sua função no restaurante e junto ao seu Severino deram conta do recado.

Além de trabalharem no restaurante, os funcionários atuam ainda em eventos realizados fora da empresa, como casamento, noivado, aniversário, buffet em geral. Ceicinha relatou que não precisa convencê-los a participarem dessas atividades extras, pois eles estão sempre a sua disposição. "Quando um termina seu serviço, prontamente, vai ajudar quem ainda não terminou. Quando acabam as tarefas no salão, já vão auxiliar na cozinha. Eles entram juntos, e fazem questão de sair juntos do restaurante. Não tem aquele negócio: ah, eu entrei de 07:30, vou sair de 15:30. E quando entra um novato, eles ajudam.", destaca a empreendedora.

"Todos eles sabem servir, todos eles sabem o que tem que fazer, todos eles atendem, todos eles sabem montar quentinha, todos eles sabem anotar pedido, e todos sabem o endereço dos clientes", complementou Ceicinha. Mesmo não existindo o cadastro de cliente no restaurante, todos os funcionários sabem o endereço da clientela, que diariamente faz pedido de quentinha. Tem cliente que nunca foi ao restaurante, só pede quentinha por telefone, mas os funcionários do Aroma da Serra só em ver a foto da pessoa no WhatsApp, já reconhecem e sabem o endereço de entrega.

O Aroma da Serra é aberto ao público das 11:00 até às 14:30. No domingo, o horário é estendido até às 15:00 horas e aos sábados não funciona. É o dia de folga dos funcionários. Antes era necessário mais uma pessoa para que eles folgassem, cada um em um dia. No entanto, ao perceber que sábado era o dia mais "fraco" de atendimento, com menor número de clientes, bem como o dia em que eles tinham maior interesse em folgar, decidiu-se por fechar o restaurante aos sábados. Além deste dia de folga, cada funcionário tem direito a um domingo por mês.

Os dias de maior movimento no restaurante são domingo e segunda, com público bem distinto: na segunda, a principal clientela são pessoas que trabalham em Areia-PB, no domingo, os clientes são todos de fora da cidade. Saem de Lagoa Seca, Campina Grande, Mamanguape, para saborear as delícias do Aroma da Serra. Para fidelizar os clientes, Ceicinha sempre busca fazer um agrado, como servir a bebida (suco ou refrigerante) de forma gratuita, ou deixar as crianças isentas no pagamento da refeição. São famílias bastante numerosas (entre 15 a 20 pessoas), que saem da sua cidade para ir almoçar no Aroma da Serra, logo a empreendedora considera relevante esse tipo de estratégia.

Os funcionários do Aroma da Serra fazem a primeira e a segunda refeição do dia no restaurante. Ceicinha relatou que antes eles gostavam muito de tomar café, no entanto, o consumo do café "tira o paladar". Então pela manhã, eles não têm o direito de tomar café. Eles tomam chá. Os que não gostam de chá, tomam suco, mas café não pode para não perder a sensibilidade do que eles estão provando enquanto cozinham. Assim, ficou estabelecido que eles só podem tomar café à tarde, no final do expediente.

Além da primeira refeição, os funcionários também almoçam no restaurante: a mesma comida que é comercializada. Ceicinha acredita que seus funcionários têm que comer a melhor comida e antes de todo mundo, porque eles têm que atender os clientes satisfeitos. Um 
dos seus funcionários inclusive é conhecido como "sorridente", porque ele ri o tempo todo. Todos eles trabalham motivados, os clientes nunca veem eles com raiva.

No restaurante Aroma da Serra não tem funcionário do mês! Ceicinha defende que todos precisam ser funcionários destaque, todos os meses. A empreendedora está sempre realizando ações de integração. Em junho e em dezembro são realizadas confraternizações muitas vezes no próprio restaurante, por decisão deles próprios. E também existe o bloco do aroma, que todo carnaval sai às ruas. As bebidas e o carro de som ficam por conta dos proprietários do restaurante, Ceicinha e Severino, e os funcionários mandam fazer a camisa do bloco e vendem. O dinheiro arrecadado é dividido entre eles mesmos.

Apesar de todos eles chegarem sem experiência, em pouco tempo eles aprenderam e deram conta do recado. Atualmente, o Aroma da Serra é composto por oito funcionários, que têm entre 20 e 30 anos, e foram treinados ao serem admitidos no restaurante. Ceicinha destacou que um era agricultor, então nunca tinha se deparado com uma cozinha, mas hoje ele é um dos melhores cozinheiros do restaurante. "É quem faz uma salada divinamente bela", segundo a empreendedora. Além dele, há também no restaurante um funcionário que antes atuava como motorista, outro que trabalhava como cobrador de ônibus, e outro que ocupava a função de gari, ou seja, todos contratados sem nenhuma experiência no segmento de alimentos e bebidas. Há também no quadro funcional do restaurante, rapazes que estão vivenciando sua primeira experiência profissional, conforme Ceicinha relatou: "esses, antes de começarem aqui, não faziam nada da vida".

A empreendedora enfatizou que "o pré-requisito para trabalhar no Aroma da Serra é querer trabalhar, porque mesmo sem saber de nada relacionada à cozinha e ao serviço de restaurante, no Aroma da Serra aprende". A primeira semana de um funcionário novato é sempre muito difícil. Precisa ter cuidado inclusive com a linguagem. Quando Severino fala: "vamos cortar a cebola em (brunoise)", Ceicinha repreende e fala: - "diga a ele: corte em cubos e bem fininho". Ceicinha explica que se você for dizer "em brunoise", "em julienne", ele não vai saber. Quando ele diz para um funcionário: "vamos fazer a cocção", Ceicinha corrige: diga "vamos cozinhar, fritar, guisar...". A empreendedora sempre pede para seu esposo se voltar para realidade dos funcionários, que não têm conhecimentos na área.

No que se refere à gestão do empreendimento, à liderança e ao relacionamento interpessoal, Ceicinha, apesar de reconhecer a importância de um curso na área de gestão, revelou que tudo que sabe e aplica em seu negócio foi aprendido na prática. Além disso, ela destaca que o fato dela ter sido criada em ambiente de comércio, por sua mãe ter loja no segmento de confecção e seu pai serproprietário de um mercadinho, ajudou bastante.

No primeiro ano do restaurante Aroma da Serra, a Ceicinha foi registrada como microempreendedora individual - MEI, no entanto, com o sucesso do negócio rapidamente ela deixou de atender os pré-requisitos do MEI, inclusive no que se refere ao registro de seus funcionários. E assim, a empresa foi registrada como microempresa - ME, cuja principal diferença está relacionada ao faturamento anual do empreendimento.

A empresa chegou a receber uma denúncia referente a trabalho de menores. Um representante do Ministério do trabalho foi até o Aroma da Serra e solicitou toda a documentação dos funcionários. No entanto, não encontraram nenhuma irregularidade. Estava tudo certo, pois todos os funcionários trabalham com carteira assinada. Ceicinha destaca que prefere ter poucos colaboradores, mas ter todos eles registrados. A empreendedora ainda 
relevou que preferiu não admitir jovem aprendiz no restaurante, para não ser responsável por menores de idade.

No Aroma da Serra todos têm salários fixos, inclusive Ceicinha, Severino e até seus filhos, já que a empreendedora todo mês faz um depósito nas poupanças das duas crianças. Ceicinha explica que eles também fazem parte do restaurante. Parte do dinheiro investido no negócio saiu da poupança de sua primeira filha, que ela precisou trabalhar por um ano para conseguir repor.

Para conseguir honrar todos os compromissos do restaurante, Ceicinha está sempre atenta às despesas e ao que pode ser otimizado na empresa para diminuí-las. A título de exemplo, a gestora decidiu trocar as cores das paredes do restaurante, ao perceber que a pintura escura demandava de maior iluminação artificial, e, consequentemente, acarretava em uma despesa elevada com energia elétrica. No entanto, essa foi a única alteração feita na estrutura física do restaurante desde o dia da sua inauguração, em quatro anos de funcionamento.

Outra despesa que foi minimizada está relacionada aos desperdícios de comida. Por ser um restaurante self-service sem balança, não é possível prever com precisão o número de refeições que serão vendidas diariamente. Há dias que são vendidos 150 almoços, em outros 200 almoços, porém, têm dias que são vendidas apenas 90 refeições. "No início, sobrava muita comida. O desperdício era enorme", relembra Ceicinha. No entanto, com o tempo, foi possível estabelecer uma base que dá para atender em média 120 pessoas e, assim, diminuiu o desperdício. De toda forma ainda há sobras de comida. Mas como não é aproveitada de um dia para o outro, são doadas para as famílias carentes que moram próximo ao restaurante, ainda que isso vá de encontro às recomendações da vigilância sanitária. Quanto ao óleo de cozinha, usado apenas na fritura da batata, ele é reutilizado para acender o fogo da churrasqueira. As latas, garrafas pets, entre outros materiais recicláveis, são separados e já tem um pessoal certo que passa para coletar. Essas são algumas iniciativas de responsabilidade ambiental e social praticadas no Aroma da Serra.

A decisão por servir apenas uma refeição (almoço) também foi estratégica. Ao longo de dois anos, o Aroma da Serra serviu almoço e jantar, no entanto, a experiência não foi positiva. Verificou-se que era muito cansativo, o que demandava uma segunda equipe, mas o restaurante não conseguia manter duas equipes de trabalho, logo sobrecarregava Ceicinha e Severino.

Atualmente, todos os funcionários chegam entre 7:30 e 8:00. Então como já estão todos bem treinados, cada um sabe o que vai fazer. Pela manhã tem o cardápio, então ao tomarem conhecimento, por exemplo, qual a salada que vai ser servida no dia, pois o restaurante serve 8 tipos que diferem ao longo da semana, então já cortam, já fazem a decoração, deixam as travessas bem apresentadas e também cortam os insumos a serem utilizados nas refeições, ou seja, fazem o pré-preparo dos insumos. No entanto, feijão, carne, arroz, isso é Severino, o chef de cozinha, quem prepara e tempera. "Segundo ele, se der uma receita de bolo a 10 pessoas, vai sair 10 bolos diferentes: vai sair um solado, um fofo, um doce, um mais amargo, então, como aqui no restaurante queremos ter um padrão, só ele tempera", destaca Ceicinha.

O Aroma da Serra prima pela qualidade de seus produtos e por isso opta pela produção artesanal de alguns preparos. A massa da lasanha e do ravióli, por exemplo, são todas feitas no próprio restaurante. Além disso, há uma preocupação também com a procedência dos 
alimentos, assim prefere-se comprar com os produtores locais: as folhagens são da plantação da comunidade Chã-Jardim; a batata e a macaxeira são compradas a um senhor que tem um sítio próximo; o feijão é comprado com outro rapaz que também faz esse plantio, em AreiaPB. Os alimentos que são comprados fora é porque não tem na cidade, como por exemplo, abacaxi, cebola e tomate.

Além de valorizar os produtores locais, há uma parceria entre os empreendedores da região. Um recomenda o serviço/produto do outro. Ceicinha destaca que tem cliente que vem conhecer Areia e por ventura almoça em seu restaurante. Quando alguém vai conhecer o Engenho Triunfo, por exemplo, a Maria Júlia (proprietária do engenho) diz: "lugar para almoçar: tem o Barretão, tem o da Vó Maria, tem o Aroma da Serra". Da mesma forma, quando vêm ao restaurante da Ceicinha ela diz: "conheçam o restaurante Vó Maria, que é lindo, é rústico, tem uma galinha de capoeira muito boa". Juntos os empreendedores locais, que fazem parte da ATURA - Associação de Turismo Rural e Cultural de Areia, "vendem" a cidade de Areia-PB. Ceicinha explica que desde que viraram uma associação, são todos parceiros.

A cidade de Areia faz parte da rota cultural "caminhos do frio". O projeto teve início em 2005, e movimenta o cenário cultural das cidades envolvidas, com apoio do SEBRAE e do Governo do Estado da Paraíba. A rota caminhos do frio tem atrações populares, festival gastronômico, turismo de aventura e cultural sendo um forte ponto para o turismo e a economia local. Na edição do ano de 2019, que aconteceu em julho, a Rota Cultural teve abertura na cidade de Areia-PB, o que configurou uma excelente oportunidade para os empreendedores locais.

\section{Decisão}

Com o passar dos anos, mesmo diante de todos os desafios, Ceicinha afirma "é muito difícil, prende muito, a gente não sai, não fazemos viagem em família, mas é muito gratificante". Ceicinha diz que o negocio é saber trabalhar, porque nem todo mundo quer trabalhar, quer abrir um negócio, sentar e esperar o dinheiro vir. Mas não é assim que funciona. $\mathrm{O}$ dono tem que estar dentro da empresa. No entanto, mesmo exigindo muita dedicação e empenho, a paixão que antes era apenas do seu esposo, Severino, tornou-se também a paixão de Ceicinha. Ela afirma: "Hoje eu não sei mais viver sem o restaurante!".

O Aroma da Serra adotou uma série de estratégias organizacionais desde sua criação. Muitos testes (horário de atendimento, equipe de trabalho, produção diária) foram realizados ao longo dos anos. Será que Ceicinha atingiu o padrão de serviço ideal para o seu restaurante? Existem conflitos nas estratégias adotadas? Existem outras estratégias organizacionais que não foram vislumbradas? Qual o caminho a ser trilhado pelo restaurante nos próximos anos?

\section{Notas de ensino}

As notas de ensino têm como objetivo orientar o professor na resolução do caso em sala de aula. Logo, serão apresentados nesta seção os objetivos didáticos ou educacionais, para delinear os temas que serão trabalhados em aula e em quais disciplinas/temas o caso se aplica, bem como as orientações para aplicação do caso em sala de aula, delimitando claramente a 
metodologia de aplicação e análise em sala de aula. Em seguida, serão apresentadas as questões a serem refletidas a partir do caso; e, logo após, os temas abordados e sugestões para a sua discussão do caso, apresentando as principais perspectivas teóricas que fundamentaram o caso e vão subsidiar a sua análise e direcionar caminhos de ação na discussão das questões.

Objetivos de Aprendizagem e Orientações para aplicação do caso em sala de aula

O caso foi estruturado para debater questões relativas ao perfil empreendedor e todo o processo de criação e estruturação organizacional de uma empresa de gestão familiar, no setor de alimentação, de uma cidade turística. Este caso é inspirado em uma situação real e foi desenvolvido no intuito de auxiliar professores dos cursos de Administração, Turismo, Hotelaria e Gastronomia, na abordagem de conteúdos relacionados ao empreendedorismo, administração estratégica, gestão de pessoas, marketing, turismo local e associações comunitárias, que fazem parte da estrutura curricular de cursos de nível técnico e superior.

Este caso pode ser utilizado como recurso didático, nesse sentido, recomenda-se discutir, antes da aplicação do caso para ensino, uma explanação ainda que superficial sobre os conteúdos apontados. No entanto, a aplicação deste caso pode ser feita tanto no início da aula como incentivo para a reflexão, despertando o interesse do aluno para a aprendizagem, quanto ao final da aula expositiva realizada pelo professor, como uma complementação das teorias e conceitos abordados.

Com o propósito de cumprir os objetivos de ensino propostos, sugere-se que os professores adotem os seguintes passos para aplicação deste caso de ensino: a) leitura individual: propor aos alunos que façam a leitura do caso de ensino - tempo estimado: 15 minutos; b) debate em pequenos grupos: estimular que os grupos de 3 ou 4 alunos debatam e discutam sobre as problemáticas descritas no caso, procurando analisar e examinar hipóteses e proposições para a solução das mesmas - tempo estimado: 10 minutos; c) apresentação em círculo: dispor a turma em círculo e solicitar que cada grupo apresente, de forma oral, a sua análise a respeito do caso e a possibilidade que julgue mais conveniente para a solução dos problemas - tempo estimado: 10 minutos; d) fechamento do caso de ensino estudado: propor uma conclusão a respeito das opiniões manifestadas pelos alunos, analisando as alternativas propostas pelos mesmos - tempo estimado: 15 minutos.

Na etapa destinada à discussão e a apresentação oral da análise de cada grupo, recomenda-se que o professor forneça aos grupos as questões descritas no tópico a seguir, a fim de incentivar a discussão e a apresentação de alternativas para a solução do conflito. É importante que o professor não forneça uma resposta definitiva para a solução do caso. $\mathrm{O}$ docente deve atuar como mediador, realizando as análises de todas as propostas apresentadas para solução do conflito, juntamente com os alunos, ponderando as vantagens e desvantagens de cada decisão.

\section{Questões para Discussão}

1. Como se deu o processo empreendedor para a abertura do Aroma na Serra? a) O que motivou os sócios a realizar o investimento na empresa? b) Havia potencial no negócio? 
2. Quais características empreendedoras você detecta em Ceicinha?

3. Quais eram os principais problemas do Aroma da Serra? Quais foram as estratégias organizacionais adotadas para solucionar estes problemas? Foram adequadas à situação?

4. Qual o nível de conhecimento dos sócios para a condução do negócio - Restaurante Aroma da Serra? da Serra?

5. Qual o nível de comprometimento e motivação da equipe de funcionários do Aroma

6. Quais as principais problemáticas que podem ser destacadas nesse caso sobre as práticas de recursos humanos e marketing?

7. Liste as prováveis soluções para os problemas enfrentados pelo Restaurante Aroma da Serra em suas diversas áreas administrativas.

8. Quais as principais estratégias que Restaurante Aroma da Serra poderia adotar? Descreva as ameaças e oportunidades, os pontos fortes e fracos.

9. Qual estratégia poderia ser adotada para atrair mais clientes no restaurante, nos dias de baixa demanda?

10. Qual a relevância da atividade turística em Areia para o Aroma da Serra?

11. Qual a relevância da associação comunitária para o Aroma da Serra?

Temas Abordados no Caso e Sugestões para a Discussão

Por meio deste caso, é possível abordar em sala de aula, conceitos básicos da administração de um restaurante, relacionados ao marketing, gestão de pessoas e estratégia organizacional; assim como, realizar reflexões acerca do turismo de base comunitária, e sobre a importância das associações nesse contexto. É possível abordar: o processo de empreender, as competências empreendedoras, a criação de uma empresa familiar e os seus conflitos; as práticas de gestão de pessoas; o processo de tomada de decisão; a evolução do ciclo de vida de uma pequena empresa; a estrutura organizacional de uma empresa no setor de alimentação; o relacionamento da empresa com seu público; o posicionamento de mercado; os as empresas o setor de alimentação dentro do sistema turístico; turismo comunitário; e associações comunitárias.

\section{- Empreendedorismo}

Ao aplicar o caso, o professor poderá iniciar as discussões a partir da análise dos tipos de empreendedorismo, os que surgem por necessidade e os que surgem por oportunidade, 
assim como, discutir as competências necessárias aos empreendedores. Dornelas (2008) cita algumas características de empreendedores de sucesso, entre as quais: visionários, hábeis em tomar decisões, determinados, dinâmicos, dedicados, otimistas, apaixonados pelo que fazem, líderes e formadores de equipe. O autor destaca que os empreendedores são planejadores, independentes, gostam de assumir riscos calculados e sabem explorar oportunidades. Características da empreendedora do caso podem ser utilizadas para ilustrar essas competências.

Além disso, é possível refletir com os alunos sobre o processo empreendedor. Dornelas (2008) descreve que esse processo ocorre em quatro fases: (a) identificar e analisar oportunidades; (b) desenvolver plano de negócio; (c) determinar e captar recursos necessários; (d) gerenciar a empresa criada. O modelo do autor pode ser utilizado para demonstrar como ocorreu o processo empreendedor do Restaurante Aroma da Serra.

- Gestão estratégica

O caso mostra alguns assuntos que podem ser trabalhados na área de marketing, na área de produção e até na área de gestão da qualidade. Aspectos em relação à definição do mix de produtos do restaurante e sua produção, à divulgação da empresa, à definição de estratégias para captação de clientes podem vir a ser discutidos com base no caso.

Ao observar todas estas questões, deve-se, na discussão em sala orientar, como sugestão, a elaboração de um plano de negócios, incluindo o plano de marketing (Kotler, 2006) para nortear as ações e superar as ameaças advindas do ambiente externo. Além disso, os gestores do Restaurante Aroma da Serra ao definirem estratégias de crescimento em um plano de ação podem vir a ampliar sua participação no cenário turístico local, inclusive por meio do estabelecimento de alianças estratégicas com o trade turístico da região.

\section{- Gestão de Pessoas}

$\mathrm{Na}$ discussão com os alunos podem ser analisadas as práticas de gestão de pessoas (recrutamento, seleção, treinamento, motivação) realizadas no Aroma da Serra e discutir outras possibilidades, pois na realidade a política de contratação adotada no restaurante se limita ao mercado de mão de obra local, contratando pessoas sem experiência e competência na área. Deve-se também discutir com os alunos os mecanismos que o restaurante pode adotar para lidar com a profissionalização da sua equipe de profissionais, pelo fato do mercado local não dispor de pessoas qualificadas.

\section{- Turismo e Associações Comunitárias}

O caso também pode ser utilizado em reflexões sobre o turismo de base comunitária (Roberto, Sansolo \& Ivan, 2010), que é um tipo de turismo no qual a comunidade se faz protagonista na atividade turística em prol do desenvolvimento da sua localidade. O relato pode contribuir para a valorização de novas alternativas para se fazer turismo. Decidir por contratar a mão de obra local, comprar os insumos que serão utilizados no restaurante aos produtores da região, fazer indicação a seus clientes de empresas "concorrentes",são aspectos 
que merecem discussão, pois vão na contramão do que é propagado no contexto competitivo e capitalista.

Além disso, o caso permite reflexões acerca da importância das associações comunitárias para o fortalecimento dos microempreendedores locais. A associação apresentada no relato, ATURA - Associação de Turismo Rural e Cultural de Areia, ilustra essa discussão.

\section{Fonte dos Dados e o Processo de Elaboração do Caso}

Os dados utilizados nesse caso foram obtidos a partir de uma entrevista semiestruturada com a empreendedora do Aroma da Serra, Ceicinha, realizada em seu restaurante, localizado em Areia-PB. O nome da empresa e dos atores organizacionais envolvidos são reais, e estão sendo utilizados neste relato com autorização prévia dos mesmos.

A entrevista durou aproximadamente duas horas e sua transcrição resultou em 43 páginas. A riqueza de detalhes do relato proporcionou a elaboração de um caso multidisciplinar, que pode vir a ser utilizado para discutir diferentes conteúdos, pertencentes a diferentes disciplinas, de diferentes cursos: administração, turismo, hotelaria e gastronomia.

Para a coleta de dados, foi um utilizado um roteiro semiestruturado, mas grande parte das perguntas emergiu durante a própria entrevista. A entrevista foi realizada pelas duas autoras do artigo simultaneamente. Apesar de ter sido utilizado um gravador de voz, a entrevistada ficou bem à vontade e respondeu com profundidade a todos os questionamentos, chegando até a se emocionar em alguns momentos, ao relatar a história do seu empreendimento.

Para a escrita do caso, foram seguidas as recomendações de Alberton e Silva (2018), que caracterizam um bom caso para ensino e os principais problemas identificados no processo de avaliação dos casos. As diretrizes apresentadas pelos autores relacionadas à delimitação dos objetivos, à relevância do caso, à apresentação das informações, à redação do texto, à qualidade das notas de ensino e à imparcialidade do pesquisador, foram levadas em consideração na elaboração deste caso.

Após o processo de escrita, foi realizada a revisão o que leva a adicionar, excluir ou modificar idéias, reescrever ou mover sentenças ou parágrafos, assim como adicionar transições para melhorar o fluxo da narração e, em seguida, o texto foi submetido à informante-chave, para comprovar a veracidade do caso e verificar falas dos personagens, conforme recomenda Roesch (2007).

\section{Conclusão}

A maioria das histórias organizacionais são relevantes e podem ser transformadas em caso. O desafio, entretanto, é saber relatá-las, tendo como finalidade objetivos educacionais. Afinal, o caso para ensino não é escrito para contar histórias tão somente; é elaborado para desenvolver habilidades de resolução de problemas nos estudantes, seja para iniciar reflexões sobre um assunto, seja para complementar o conteúdo ensinado em aulas expositivas.

Compreendendo a relevância de um caso para ensino enquanto recurso didático, somado a dificuldade em encontrar casos que reproduzam o processo de empreender, a trajetória e os 
desafios inerentes a este processo, surgiu o interesse em elaborar este trabalho, que se configura como um caso multidisciplinar que pode vir a ser utilizado para discutir diferentes conteúdos, pertencentes a diferentes disciplinas, de diferentes cursos: administração, turismo, hotelaria e gastronomia.

Por fim, é pertinente destacar que há uma escassez de casos para ensino a serem aplicados nos cursos turismo, hotelaria e gastronomia. Assim, espera-se que este caso sirva de estímulo para que outros estudantes, pesquisadores e docentes também se motivem a escrever casos sobre os mais diversos conteúdos, pois a aprendizagem é significativa tanto para quem analisa o caso, quanto para quem o escreve.

\section{Referências}

Alberton, A., \& da Silva, A. B. (2018). Como Escrever um Bom Caso para Ensino? Reflexões sobre o Método. RAC-Revista de Administração Contemporânea, 22(5), 745-761.

Dornelas, J. C. A (2008). Empreendedorismo: transformando ideias em negócios. 3 ed. Rio de Janeiro: Elsevier.

Kotler, P. K. (2006). KL Administração de marketing. Tradução de Mônica Rosenberg, Cláudia Freire e Brasil Ramos Fernandes. São Paulo: Pearson.

Roberto, B., Sansolo, D. G., \& Ivan, B. (2010). Turismo de Base Comunitária, diversidades de olhares e experiências brasileiras.

Roesch, S. M. A. (2007). Notas sobre a construção de casos para ensino. Revista de Administração Contemporânea, 11(2), 213-234. 